\title{
Endogenous Antinociceptive System and Potential Ways to Influence It
}

\author{
A. YAMAMOTOVÁ ${ }^{1}$ \\ ${ }^{1}$ Department of Physiology, Third Faculty of Medicine, Charles University, Prague, Czech Republic
}

Received March 21, 2019

Accepted September 26, 2019

\section{Summary}

The biological significance of pain is to protect the organism from possible injury. However, there exists a situation, where, in the interest of survival, it is more important not to perceive pain. Spontaneous suppression of pain or weakening of nociception is mediated by an endogenous antinociceptive (analgesic) system. Its anatomical substrate ranges from the periaqueductal gray matter of the midbrain, through the noradrenergic and serotonergic nuclei of the brain stem to the spinal neurons, which receive "pain" information from nociceptors. Moreover, the activity of this system is under significant control of emotional and cognitive circuits. Pain can be moderated primarily through stimulation of positive emotions, while negative emotions increase pain. Paradoxically, one pain can also suppress another pain. Analgesia can be induced by stress, physical exercise, orosensory stimulation via a sweet taste, listening to music, and after placebo, i.e. when relief from pain is expected. Since pain has sensory, affective, and cognitive components, it turns out that activation of these entire systems can, in specific ways, contribute to pain suppression.

\section{Key words}

Antinociceptive system • Analgesia • Stress • Diffuse noxious inhibitory control

\section{Corresponding author}

A. Yamamotová, Charles University, Third Faculty of Medicine, Department of Physiology, Ke Karlovu 4, 12000 Prague 2, Czech Republic. E-mail: yamamoto@lf3.cuni.cz

\section{Introduction}

Pain is a complex process that has sensory, affective, and cognitive components. It also affects the activity of the autonomic nervous system, neuroendocrine system, and behavior. While acute pain has a mostly positive function when warning the body against potential injury or tissue damage, chronic pain is a condition without any biological significance that worsens the quality of life of those affected and is frequently accompanied by depressive states. Pain mechanisms have much in common with stress mechanisms, i.e. acute pain represents acute stress and chronic pain chronic stress. In both cases, various homeostatic mechanisms are activated to ensure that the organism manages these situations optimally. Therefore, pain is now seen as a homeostatic emotion (Craig 2003). However, unlike other sensory modalities, pain is unpleasant at threshold intensities. Moreover, acute pain induces negative emotions and is uncomfortable, all while serving a significant biological function, i.e. it activates patterns of behavior that protect the body from further injury.

In pain, unlike other perceptions, the relationship between the intensity of the nociceptive stimulus and the intensity of subjectively felt pain is not necessarily linear. For example, it is not uncommon for even serious injuries to cause little or no pain. The question is, what causes pain to be spontaneously inhibited in certain cases, and where does the suppression occur?

There are several regions of the central nervous system (CNS) associated with pain control. Pain can be reduced at the peripheral level, the spinal cord, and supraspinal structures, however, since its function is to warn of potential injury, the ratio of pronociceptive and antinociceptive processes is set to limit and constrain 
antinociception under normal conditions. However, there are conditions in which the ability to not feel pain becomes a necessity, i.e. when the organism must activate mechanisms that are important for adaptation and in extreme survival situations.

\section{Stress-induced analgesia}

The trigger region for each stress response is activation of paraventricular (PVN) and supraoptic nuclei of the hypothalamus, which produce corticotropinreleasing hormone (CRH), vasopressin, and oxytocin. While the afferentation of supraoptic oxytocin neurons is relatively poor and includes mainly painless somatosensory and visceral afferentation from the periphery and central afferentation from the structures of the limbic system, neurons that convert all sensory modalities including pain transmission participate in the activation of PVN with subsequent $\mathrm{CRH}$ production (Sawchenko et al. 1996).

When processing the stress stimulus, a cascade of events is initiated consisting of the gradual activation of the hypothalamic-pituitary-adrenal axis. In reality, it involves the coactivation of two different interacting systems, the hypothalamo-pituitary-adrenal/cortisol system, and the sympatho-adreno-medullar system. There is positive feedback between the PVN, which releases $\mathrm{CRH}$, and the noradrenergic locus coeruleus. $\mathrm{CRH}$ stimulates the production of noradrenalin, which further stimulates the formation of $\mathrm{CRH}$; additionally, both dampen their production (Stanford 1995). CRH release can also be enhanced by acetylcholine and serotonin, while GABA and opioids inhibit CRH secretion. The intensity of the stress response is largely dependent on feedback control mechanisms. Classic glucocorticoid feedback consists of inhibiting the formation of ACTH and $\mathrm{CRH}$; however, it was found that cortisol can also inhibit noradrenergic neurons and thus weaken their stimulatory effect on CRH production (Pacak et al. 1995). In some types of stress, the stress response is potentiated by vasopressin, which, like $\mathrm{CRH}$, stimulates ACTH production (Kjaer 1993). The intensity of the stress response can be selectively modulated by the opioid system via stimulation of metenkephalin and dynorphin on sympathoadrenergic activity and the inhibitory effect of $\beta$-endorphin (Fontana et al. 1997).

Opioid neurons in the brain are distributed in three functional circuits: the nigrostriatal and mesolimbic dopaminergic system, the hypothalamo-pituitary axis, and the descending antinociceptive system (Simon and Hiller 1994). All three areas are activated under stress, but the latter plays a major role in pain modulation. The antinociceptive descending system includes the midbrain, the medulla, and the spinal cord. Hierarchically, the highest center is the periaqueductal gray (PAG) in the mesencephalon. Very strong analgesia can be induced through electrical stimulation, morphine application, or glutamate microinjections into this region (Carstens et al. 1990).

\section{The role of periaqueductal gray}

PAG neurons receive numerous inputs directly from the cortex, hypothalamus, and amygdala (Bandler and Keay 1999, Vianna and Brandão 2003). Also, it receives afferentation from lower brain regions such as nucleus tractus solitarius (NTS) and parabrachial nuclei (Roeder et al. 2016). PAG neurons do not transmit projections to the spinal cord directly. They do so via the brain stem where it affects the activity of serotonergic and noradrenergic neurons located in the rostroventromedial medulla (Lau and Vaughan 2014, Chen et al. 2017, Tobaldini et al. 2019).

Additionally, there are cells in this area referred to as pronociceptive "on" and antinociceptive "off" cells. These neurons were first discovered during painful stimulation of rats with electrodes implanted to register unit activity. Pronociceptive "on" cells were always activated, while antinociceptive "off" cells were inhibited before a painful defense response (Neubert et al. 2004, Carlson et al. 2005, Heinricher et al. 2008).

The internal functional organization of the PAG is divided into ventrolateral and lateral regions, which are activated by different types of pain. The ventrolateral PAG is activated by deep somatic and visceral pain, while the lateral PAG receives nociceptive information from the body surface, such as nerve endings in the skin. The afferentation of the ventrolateral PAG comes mainly from the spinal cord and NTS, but it lacks somatotopic organization, which is also consistent with the fact that visceral pain is not precisely localized. The lateral PAG receives afferents from the spinal cord, as well as from the trigeminal nuclei, although, these follow clear somatotopic projections. Electrical stimulation of different parts of the PAG induces different autonomic reactions and behavior. These responses can manifest as hypotension, bradycardia, and passive defense reactions (freezing) during stimulation of the ventrolateral PAG 
and as hypertension, tachycardia, and active stress coping ("fight or flight" reaction) during stimulation of the lateral PAG (Bodnar et al. 1980, Bodnar 2000, Vianna and Brandão 2003, George et al. 2019).

Both types of behavior are associated with analgesia, but their mechanisms are different. The analgesia induced by ventrolateral PAG stimulation can be described as opioid, whereas stimulation of the lateral PAG induces non-opioid analgesia. These different mechanisms of analgesia have been extensively studied in rats using swim stress. The involvement of the opioid or non-opioid system depended on swimming time and water temperature. Swimming in cold water (about $2^{\circ} \mathrm{C}$ ) or long-term swimming, independent of water temperature (more than $5 \mathrm{~min}$ ), caused analgesia that was blocked by MK-801 (a non-competitive antagonist of glutamate NMDA receptors), which suggested a nonopioid type of analgesia. Conversely, swimming in warmer water $\left(20-32{ }^{\circ} \mathrm{C}\right)$ or short-term swimming, induced analgesia that was blocked by naloxone (an opioid receptor antagonist) and thus suggesting an opioid-type of analgesia (Terman et al. 1984). Although it is difficult to unambiguously establish a sharp boundary between opioid and non-opioid analgesia, numerous animal experiments indicate that most weak stressors cause opioid analgesia, whereas very strong stressors cause non-opioid analgesia.

What is the biological significance of different analgesia systems? These mechanisms were studied by Bodnar et al. (1980), who developed the so-called collateral inhibition model for pain control systems. It assumes that there is a specific hierarchy in the antinociception system that prevents both types of analgesia from being activated simultaneously. If one system is more active, it will dampen the other system, i.e. the opioid system inhibits the non-opioid system via collateral inhibition and vice versa. A similar mechanism is at work in sensory systems to enhance "signal-tonoise" contrast in which the most activated neurons inhibit their less active neighbors. Bodnar also suggests that this arrangement might have some adaptive purpose, since the pattern of behavior that is more significant at the same time, not only in terms of pain suppression but also in terms of better coping with the situation under which the pain arose, will be most activated.

In men, deep brain stimulation of the periaqueductal gray is used in the treatment of intractable phantom limb pain or anesthesia dolorosa which are refractory to pharmacotherapy. PET scan showed that stimulation of the $\mathrm{PAG}$ reduced radioligand binding through the release of endogenous opioids but this did not correlate significantly with pain reduction (SimsWilliams et al. 2017).

Measurement of heart rate variability during stimulation of ventral PAG in patients with chronic neuropathic pain showed changes in LF/HF ratio (increase in parasympathetic activity) which correlated significantly with reported analgesia (Pereira et al. 2010). Analgesic or antinociceptive effects are similar to vagal stimulation, which also attenuates pain (Bohotin et al. 2003).

\section{Physical exercise as a stressor}

When something hurts, movement in the affected part of the body is reduced, thereby protecting the body from further injury. In the case of non-adaptive chronic pain, the behavior is generally affected, and physical activity is significantly reduced. In contrast, active athletes and ballet dancers have been repeatedly shown to be less sensitive to pain (Guieu et al. 1992, Tajet-Foxell and Rose 1995, Farasyn and Meeusen 2003). However, even in untrained individuals, aerobic and isometric exercise has been shown to weaken the perception of pain stimuli from various modalities (Janal 1996, Gajsar et al. 2017). Physical exercise is also a stressor (Koltyn 2000, Gerber et al. 2017) and the analgesic system most activated will depend on, among others, the intensity, type, and length of exercise.

\section{Opioid system}

The response of the opioid system changes after exercise. A study conducted in rats with sciatic nerve ligation, which induces hyperalgesia, showed that if these animals were allowed to run in running wheels, their pain threshold did not differ from that of the control rats (Stagg et al. 2011). In addition, in rats allowed to run, the level of beta-endorphin and met-enkephalin, in rostroventromedial medulla (RVM), increased significantly compared to the restricted from running group. After intense physical activity, the release of endogenous opioid peptides increases and signal transduction, through $G$ protein activation of $\mu-, \delta$ - and $\kappa$-opioid receptors, increases, particularly in the sensorimotor cortex and hippocampus (Arida et al. 2015).

Simultaneous involvement of the opioid system in the modulation of both pain and locomotor activity was demonstrated in an experiment conducted on female 
mice selected according to the amount of running wheel activity. After blocking opioid receptors with naltrexone in parallel with a reduced thermal threshold, the amount of locomotor activity was reduced in both selected lines (Li et al. 2004).

People who regularly run describe a feeling of euphoria "runner's high" that is associated with the activity. In a volunteer group, a PET study using $\left[{ }^{18} \mathrm{~F}\right] \mathrm{FDPN}$, which is a radioligand with approximately the same affinity for all types of opioid receptors, was performed before and after a half marathon (Boecker et al. 2008). At the finish, they were asked to evaluate the intensity of the euphoria induced by running using a visual analog scale. The more intense the euphoria experienced after the run, the greater the difference in opioid receptor occupancy with radioligand compared to their baseline. This difference was especially obvious in the anterior cingulate cortex, orbitofrontal cortex, and insula, where opioid receptor occupancy by the radioligand was negatively correlated with euphoria. The more receptors occupied by endogenous opioid peptides, the more intense the euphoria they experienced.

\section{Non-opioid systems}

Since it has been shown that exercise alters noradrenaline, dopamine, and serotonin levels, it appears that the monoaminergic system may also contribute to analgesia (Meeusen and De Meirleir 1995). The descendent antinociceptive system includes the noradrenergic pathways from the locus coeruleus that project to the dorsal horns of the spinal cord and synapse with second-order neurons of the pain pathway. The analgesic effect is mediated by alpha-2 adrenergic receptors. During exercise, the locus coeruleus is activated from proprio- and baroreceptors via NTS as well as CRH. The effect leads to impaired detection and discrimination of sensory stimuli. LC neurons send their axons to the ventral tegmental area (VTA), where, through activation of alpha-1 receptors, they stimulate glutamate release, which in turn increases the activity of dopaminergic neurons (Clark et al. 1986, Devilbiss et al. 2012, McMorris 2016).

\section{Endocannabinoid system}

Modulation of pain by stimulating cannabinoid receptors can be done peripherally or centrally. Endogenous cannabinoids in the CNS bind to cannabinoid CB1 receptors, which are mostly found in the dorsal root ganglia, superficial layers of the Rexed zones in the spinal cord, the RVM, and PAG (Maione et al. 2006). At the level of the spinal cord, the transmission of pain is reduced due to decreased release of glutamate from nociceptive neurons. In the PAG, endocannabinoids inhibit GABAergic neurons, and therefore, the disinhibited PAG neurons activate the descending antinociceptive system (Aubrey et al. 2017). Binding of endocannabinoids to receptors can lead to (1) the opening of potassium channels along the cell membrane causing hyperpolarization or (2) blockade of calcium channels at the presynaptic terminal. Both mechanisms reduce the release of mediator from presynaptic terminals (Maione et al. 2006).

In 2003, the first work that recorded increased levels of anandamide in the blood after intense exercise was published (Sparling et al. 2003). Since then, many parallel animal and human studies have been performed to elucidate the cannabinoid mechanism in analgesia. In rats, aerobic exercise increases cannabinoid receptor expression and arachidonoylglycerol (2-AG) and anandamide (AEA) levels in the PAG. In contrast, CB1 or $\mathrm{CB} 2$ receptor blockade before exercise does not induce analgesia (Galdino et al. 2014). In humans who had to perform submaximal isometric exercises, the mechanical pain threshold was significantly increased after exercise, the subjectively experienced pain intensity decreased, and the level of endogenous cannabinoids (AEA, 2-AG and others) increased, regardless of whether the opioid system was blocked, using naltrexone, before exercise (Koltyn et al. 2014).

\section{Pain relief by other pain}

Diffuse noxious inhibitory control (DNIC) is a pain-modulatory mechanism that reflects the activity of the descending endogenous analgesia system. It represents an attempt to objectify performance of the endogenous pain control system, i.e. to test the balance between facilitatory and inhibitory processes and thus to estimate the size of the individual analgesic potency (Pud et al. 2009, Yarnitsky et al. 2010). Currently, the term has been replaced by the expression, conditioned pain modulation (CPM). The method is based on the observation that one pain can suppress another pain and involves the measurement of thermal or mechanical pain thresholds (test stimuli) at rest and then during simultaneous conditioned cold or mechanical pain stimulation (i.e. the cold pressor test and the tourniquet method) on the contralateral limb. If the integrity of the 
endogenous analgesic system is maintained, then the pain threshold during and after tonic pain stimulation is increased. In healthy people, DNIC has been shown to be stronger in men than in women and was not dependent on personality characteristics or degree of distraction. In contrast, DNIC is attenuated in patients with chronic pain of various etiologies (Nijs et al. 2012, Wilder-Smith et al. 2010). It is believed that an attenuated DNIC may also be one of the causes of chronic pain (Pud et al. 2009, Sprenger et al. 2011) and the clinical implications of testing for DNIC efficiency might identified patients with higher risk for development of post-operative chronic pain (Yarnitsky et al. 2008).

Active athletes have, in addition to increased resting pain thresholds, greater hypoalgesia after CPM compared to non-sporting individuals (Ellingson et al. 2014, Lemley et al. 2015, Flood et al. 2017). It should be noted, however, that increased inhibitory capacity can also play a negative role since weakened negative signals sent out from the body or signals arriving late can cause overestimation of their strength and lead to injury.

\section{Pain, pleasure, and expectation}

The study of the role of dopamine in analgesia suggests that both types of analgesia, i.e. opioid and nonopioid, seem to represent only the extreme poles of a continuum. In many cases, the two systems overlap each other. There are areas of reward and punishment within the limbic system in which dopamine plays a pivotal role and in which it also plays an important role in suppressing tonic pain (Borsook et al. 2007, Leknes and Tracey 2008, Meyer et al. 2009). Mesolimbic dopaminergic neurons of the VTA project into various areas of the forebrain, including the nucleus accumbens (Altier and Stewart 1999). This pain control system is activated under stress by releasing endogenous opioids which cause the indirect release of dopamine from these neurons through inhibition of GABAergic neurons (Johnson and North 1992, Koob 1992).

The first evidence that pain stimulation may induce analgesia under specific circumstances was reported by Gear et al. (1999). Their observation led them to the idea that under certain conditions, even painful stimuli can be "rewarding", i.e. the stimuli can activate the reward system. They found that intense pain caused by subcutaneous administration of capsaicin or by immersing a limb in hot water can weaken some nociceptive reflexes for an extended period or can increase the mechanical pain threshold. The antinociceptive effect can be blocked by prior administration of either the dopaminergic antagonist, flupentixol or by the opioid antagonist, naloxone. Other experiments in anesthetized animals have shown that the antinociceptive effect was correlated with the intensity of the painful stimulus; more intense stimuli induce stronger subsequent analgesia (Gear et al. 1999). This form of analgesia can be weakened by the administration of the GABA A receptor agonist, muscimol to the rostral ventromedial medulla, but not by naloxone (Killian et al. 1995).

In our previous study we have shown that individuals with body modifications as well as without body modifications had higher thermal pain thresholds during public demonstration of painful techniques compared to thresholds measured at control neutral conditions. These observations lead us to conclude that in emotionally charged environment, pain threshold in our participants was top-down modulated via affective and cognitive processes (Yamamotová et al. 2017).

Relief from pain can be achieved even without any manipulation, using a placebo. Thus, activation of descending controls is associated with a more complex psychological phenomena and is dependent on expectation (Benedetti et al. 2005, Benedetti and Amanzio 2013). Placebo analgesia is a condition in which pain is eliminated or reduced after administration of a substance without any pharmacological effect. The placebo effect can be both analgesic and algesic, i.e. if a chemically inactive substance is claimed to cause pain, a specific group of people will experience pain. A negative effect of a placebo is referred to as a nocebo. Endogenous opioids have been implicated in the mechanism of action of placebo analgesia, whereas opioid receptor antagonists, e.g. naloxone, have been shown to weaken the analgesic placebo effect. On the other hand, the CCK receptor antagonist, proglumide, enhances both the effect of opioids and the analgesic placebo effect, but only in placebo responders; in nonresponders, proglumide has no effect (Benedetti 1996, Benedetti and Amanzio 1997).

More recent studies have shown that the dopaminergic system is activated simultaneously with the opioid system. Placebo-induced activation of opioid neurotransmission was detected in the anterior cingulate, orbitofrontal and insular cortices, nucleus accumbens, amygdala, and PAG. Dopaminergic activation has been observed in the ventral basal ganglia, including the 
nucleus accumbens. A PET study showed that dopaminergic D2/D3 mediated receptor activity and $\mu$-opioid activity correlated positively in the nucleus accumbens (Scott et al. 2008)

\section{Pain as a route to escape from reality}

The body should be a source of satisfaction and pleasure for man, with feelings that allow us to enjoy life and make it pleasant. On the other hand, dissatisfaction with one's body may increase suffering and increase selfdestructive tendencies. Negative life events accompanied by physical and mental trauma can change the perception of one's body and attitude towards it, such that the body will be rejected, hated, damaged, and destroyed. Such individuals are less susceptible to physical pain but also other bodily processes (Fishbain et al. 2001). Avoiding and escaping physical and mental reality is a way to cope with the unmanageable emotional consequences of trauma, this condition is referred to as dissociation. Dissociation is also defined as an inability to normally interpret information and experiences, a condition manifested by amnesia, depersonalization, and derealization.

The same three principal components that characterized different aspects of pain can be observed in dissociative states. If we regard dissociation as a defense mechanism that is activated in marginal situations, then the sensory component of dissociation will protect against pain (analgesia), the affective component of dissociation will protect against negative emotions, and the cognitive component of dissociation (amnesia) will prevent memories of traumatic events accompanied by pain.

Similar insensitivity to pain has been reported in young people who have survived suicide attempts compared to individuals of equal age with similar types of injuries that were unrelated to suicide, e.g. an accidental fall from height (Orbach et al. 1997). Their pain threshold was positively correlated with depression, anxiety, dissociation, and a negative relationship to one's body.

\section{The role of the sensory systems}

The most natural analgesic, although not as effective in adults, is an intake of food or drink with a sweet taste. A review on the effect of sucrose on pain in young children showed that the heart rate and negative emotional manifestations, including crying, were reduced in addition to a reduction in pain (Stevens and Ohlsson 2000, Harrison et al. 2010). The "sweet-induced" analgesia is mediated by the opioid system, and carbohydrate intake has been shown to increase morphine-induced analgesia in rats. Testing this effect by administering sucrose and saccharin showed that morphine-induced analgesia was significantly greater in sucrose-fed rats than in rats consuming a standard-diet (Kanarek and Homoleski 2000, Eikemo et al. 2016).

In addition to orosensory stimulation, olfactory stimulation can also participate in pain suppression. The increased thermal pain threshold in the lemon essential oil odor exposed rats indicated the ability of olfactory stimulation to affect pain pathways and brain areas related to pain modulation (Ceccarelli et al. 2004). In mice exposed to linalool (odorous components of lavender extract), immunohistochemical analysis revealed that odor-induced analgesia is probably mediated by hypothalamic orexin neurons (Tashiro et al. 2016).

The importance of visual perception in evaluating pain was shown by experiments conducted in people who were blind from birth (Slimani et al. 2013). In addition to reduced sensory pain thresholds, these individuals subjectively experienced more intense pain during stimulation than healthy subjects. However, thresholds for non-painful mechanical or thermal stimuli were the same as in healthy controls. Similar results can be observed in healthy people after prolonged visual deprivation (Zubek et al. 1964). These findings show how vision is critical in detecting threatening stimuli, especially painful stimuli. New anatomical studies provide evidence of the existence of a pathway connecting the anterior cingulate cortex with a key area (Brodmann area 19) involved in the processing of painful stimuli in the visual cortex (Vogt and Pandya 1987).

Patients with low back pain often have difficulty in precisely defining the part of the back that hurts because they perceive the painful area as being dimensionally altered. Common mechanisms of pain perception relative to the body do not lie at the periphery but in the CNS, and hence, pain becomes an integral part of the multimodal representation of our body. Currently, methodological procedures are developed to study both the perception of pain and the body's organization.

Diers et al. (2016) published a study showing that visual feedback can reduce pain. They focused on patients with chronic back pain, and because we do not see our backs, they used a camera to photograph the 
patient from behind and transmit the image of their back to a monitor while producing a painful stimulus. Patients with chronic pain evaluated the stimuli as more painful than healthy persons, but when using visual feedback, they perceived the stimuli as being significantly less painful. This experiment implies that looking at a painful area may weaken the aversive experience of the stimulus and may result in the stimulus being considered as less threatening. The authors believe that this method could be used to train and diminish pain perception in patients with chronic pain.

Moseley et al. (2008) showed how pain could be managed in patients with chronic upper limb pain. Patients were tasked with exercising the affected arm and recording the perceived pain intensity. They looked at the exercising hand either with magnifying glasses or with minimizing glasses. Looking at the twice enlarged hand not only caused stronger pain, but the hand swelled more after exercise, on the other hand, the pain was perceived as much weaker when the painful hand was seen as being diminished in size.

\section{Body perception and pain suppression}

An interesting finding was described in a study Gallace et al. (2011) which focused on pain perception in the hands, depending on their position relative to the body, i.e. whether they are side by side or crossed. In this context, a new concept of "cross-hand analgesia" is being introduced. The theoretical basis of this experiment was based on the fact that pain experience depends on a complex interplay between anatomical and spatial representation. They showed that merely crossing the arms across the centerline of the body weakens pain perception and increases pain thresholds when stimulated. The likely explanation for this phenomenon is a mismatch between the two reference frameworks of body perception that help localize external stimuli. One reference frame is anatomical (where on the body) and the other is spatial (where in space). Normally, these two systems provide similar information; however, when the hands are crossed across the center axis of the body the information processed by both systems is confusing. Experiments using evoked potential analysis showed that there is a delay in stimulus processing when arms are crossed. This hypothesis was confirmed by findings from fMRI studies (Torta et al. 2013). During painful stimulation of crossed arms, the posterior parietal cortex was activated less than during stimulation of uncrossed arms.
In contrast, areas that were responsible for attention, homeostasis, and physical representation, i.e. the frontal and cingulate cortex and insula, were more active when the hands were crossed. Thus, how intensely something will hurt us depends not only on the arm stimulated but also where, in space, the arm is located relative to the central axis. Moreover, crossed arms are part of a defensive posture, which is sometimes used to face a threat that could be injurious. Therefore, the increased pain threshold in this posture may also signal the onset of activation of the endogenous antinociceptive system.

Perceptual distortion can also include phantom pain, where patients after amputation experience severe pain in a non-existent limb. Because to see means to feel less pain, the mirror technique, or "Mirror Therapy" (MT) is often a helpful technique for rehabilitation purposes, especially for patients with this type of problem. Mirror therapies are based on the principle that the patient has an amputated limb hidden behind a mirror and then tries to make synchronized movements of both limbs while observing the healthy limb in the mirror. In this situation, there is a conflict between visual feedback from the supposed movement of a non-existing limb and proprioceptive feedback from the healthy limb. Information about the apparent movement of the amputated limb can significantly reduce the activity of the pain management system (Foell et al. 2014). The activity in primary motor areas contralaterally increases to the affected side, and subsequently, the pain intensity in the affected limb is reduced; it is better to prevent phantom pain than heal it. Several studies have also been performed in this context to show that the use of MT before a planned amputation can reduce the risk of phantom pain after the procedure (Hanling et al. 2010). The illusion induced by the reflection of the movement of the healthy limb in the mirror can activate the system of mirror neurons in the brain. This system represents a basic brain mechanism that transforms sensory representations of others' behavior into one's own motor representations concerning that behavior (Rizzolatti and Sinigaglia 2016).

In conclusion, our understanding of antinociception or endogenous analgesia is now undergoing an evolution that is similar to the one that transformed our understanding of stress. Stress has long been considered a nonspecific adaptive response to stressors. Only in recent years have we seen more and more evidence of its specificity, which is manifested in 
different degrees of different stressors with different functions. Regarding antinociception, which was originally considered a nonspecific defense response to pain, it now appears that there is some specificity depending on how intense the pain is, how it is induced, in what context it is evaluated, and the optimal way to face it. Although the "common final path" might be similar, consisting primarily of the activation of the opioid and dopaminergic systems, the routes that activate them can be different.

\section{Conflict of Interest}

There is no conflict of interest.

\section{Acknowledgements}

Supported by OPVVV PharmaBrain CZ.02.1.01/0.0/0.0/ 16_025/0007444 and PROGRES Q35.

\section{References}

ALTIER N, STEWART J: The role of dopamine in the nucleus accumbens in analgesia. Life Sci 65: 2269-2287, 1999.

ARIDA RM, GOMES DA SILVA S, DE ALMEIDA AA, CAVALHEIRO EA, ZAVALA-TECUAPETLA C, BRAND S, ROCHA L: Differential effects of exercise on brain opioid receptor binding and activation in rats. J Neurochem 132: 206-217, 2015.

AUBREY KR, DREW GM, JEONG HJ, LAU BK, VAUGHAN CW: Endocannabinoids control vesicle release mode at midbrain periaqueductal grey inhibitory synapses. $J$ Physiol 595: 165-178, 2017.

BANDLER R, KEAY KA: Periaqueductal gray matter, midbrain. In: Elsevier's Encyclopedia of Neuroscience. ADELMAN G, SMITH BH (eds), 1999: CD-ROM v 1.1.

BENEDETTI F, AMANZIO M: The neurobiology of placebo analgesia: from endogenous opioids to cholecystokinin. Prog Neurobiol 52: 109-125, 1997.

BENEDETTI F, AMANZIO M: Mechanisms of the placebo response. Pulm Pharmacol Ther 26: 520-523, 2013.

BENEDETTI F, MAYBERG HS, WAGER TD, STOHLER CS, ZUBIETA JK: Neurobiological mechanisms of the placebo effect. $J$ Neurosci 25: 10390-10402, 2005.

BENEDETTI F: The opposite effects of the opiate antagonist naloxone and the cholecystokinin antagonist proglumide on placebo analgesia. Pain 64: 535-543, 1996.

BODNAR RJ, KELLY DD, BRUTUS M, GLUSMAN M: Stress-induced analgesia: neural and hormonal determinants. Neurosci Biobehav Rev 4: 87-100, 1980.

BODNAR RJ: Supraspinal circuitry mediating opioid antinociception: antagonist and synergy studies in multiple sites. J Biomed Sci 7: 181-194, 2000.

BOECKER H, SPRENGER T, SPILKER ME, HENRIKSEN G, KOPPENHOEFER M, WAGNER KJ, VALET M, BERTHELE A, TOLLE TR: The runner's high: opioidergic mechanisms in the human brain. Cereb Cortex 18: 2523-2531, 2008.

BOHOTIN C, SCHOLSEM M, MULTON S, MARTIN D, BOHOTIN V, SCHOENEN J: Vagus nerve stimulation in awake rats reduces formalin-induced nociceptive behaviour and fos-immunoreactivity in trigeminal nucleus caudalis. Pain 101: 3-12, 2003.

BORSOOK D, BECERRA L, CARLEZON WA JR, SHAW M, RENSHAW P, ELMAN I, LEVINE J: Rewardaversion circuitry in analgesia and pain: implications for psychiatric disorders. Eur J Pain 11: 7-20, 2007.

CARLSON JD, SELDEN NR, HEINRICHER MM: Nocifensive reflex-related on- and off-cells in the pedunculopontine tegmental nucleus, cuneiform nucleus, and lateral dorsal tegmental nucleus. Brain Res 1063 : 187-194, 2005.

CARSTENS E, HARTUNG M, STELZER B, ZIMMERMANN M: Suppression of a hind limb flexion withdrawal reflex by microinjection of glutamate or morphine into the periaqueductal gray in the rat. Pain 43: 105-112, 1990.

CECCARELLI I, LARIVIERE WR, FIORENZANI P, SACERDOTE P, ALOISI AM: Effects of long-term exposure of lemon essential oil odor on behavioral, hormonal and neuronal parameters in male and female rats. Brain Res 1001: 78-86, 2004. 
CHEN Q, ROEDER Z, LI MH, ZHANG Y, INGRAM SL, HEINRICHER MM: Optogenetic evidence for a direct circuit linking nociceptive transmission through the parabrachial complex with pain-modulating neurons of the rostral ventromedial medulla (RVM). eNeuro 4: pii: ENEURO.0202-17.2017, 2017.

CLARK WC, YANG JC, JANAL MN: Altered pain and visual sensitivity in humans: the effects of acute and chronic stress. Ann N Y Acad Sci 467: 116-129, 1986.

CRAIG AD: A new view of pain as a homeostatic emotion. Trends Neurosci 26: 303-307, 2003.

DEVILBISS DM, WATERHOUSE BD, BERRIDGE CW, VALENTINO R: Corticotropin-releasing factor acting at the locus coeruleus disrupts thalamic and cortical sensory-evoked responses. Neuropsychopharmacology 37: 2020-2030, 2012.

DIERS M, LÖFFLER A, ZIEGLGÄNSBERGER W, TROJAN J: Watching your pain site reduces pain intensity in chronic back pain patients. Eur J Pain 20: 581-585, 2016.

EIKEMO M, LøSETH GE, JOHNSTONE T, GJERSTAD J, WILLOCH F, LEKNES S: Sweet taste pleasantness is modulated by morphine and naltrexone. Psychopharmacology (Berl) 233: 3711-3723, 2016.

ELLINGSON LD, KOLTYN KF, KIM JS, COOK DB: Does exercise induce hypoalgesia through conditioned pain modulation? Psychophysiology 51: 267-276, 2014.

FISHBAIN DA, CUTLER RB, ROSOMOFF HL, ROSOMOFF RS: Pain-determined dissociation episodes. Pain Med 2: 216-224, 2001.

FLOOD A, WADDINGTON G, THOMPSON K, CATHCART S: Increased conditioned pain modulation in athletes. J Sports Sci 35: 1066-1072, 2017.

FOELL J, BEKRATER-BODMANN R, DIERS M, FLOR H: Mirror therapy for phantom limb pain: brain changes and the role of body representation. Eur J Pain 18: 729-739, 2014.

FONTANA F, BERNARDI P, PICH EM, BOSCHI S, DE IASIO R, SPAMPINATO S, GROSSI G: Opioid peptide modulation of circulatory and endocrine response to mental stress in humans. Peptides 18: 169-175, 1997.

GALDINO G, ROMERO TR, SILVA JF, AGUIAR DC, DE PAULA AM, CRUZ JS, PARRELLA C, PISCITELLI F, DUARTE ID, DI MARZO V, PEREZ AC: The endocannabinoid system mediates aerobic exercise-induced antinociception in rats. Neuropharmacology 77: 313-324, 2014.

GALLACE A, TORTA DM, MOSELEY GL, IANNETTI GD: The analgesic effect of crossing the arms. Pain 152: 1418-1423, 2011.

GEAR RW, ALEY KO, LEVINE JD: Pain-induced analgesia mediated by mesolimbic reward circuits. $J$ Neurosci 19: 7175-7181, 1999.

GEISSER ME, WANG W, SMUCK M, KOCH LG, BRITTON SL, LYDIC R: Nociception before and after exercise in rats bred for high and low aerobic capacity. Neurosci Lett 443: 37-40, 2008.

GEORGE DT, AMELI R, KOOB GF: Periaqueductal gray sheds light on dark areas of psychopathology. Trends Neurosci 42: 349-360, 2019.

GUIEU R, BLIN O, POUGET J, SERRATRICE G: Nociceptive threshold and physical activity. Can J Neurol Sci 19: 69-71, 1992.

HANLING SR, WALLACE SC, HOLLENBECK KJ, BELNAP BD, TULIS MR: Preamputation mirror therapy may prevent development of phantom limb pain: a case series. Anesth Analg 110: 611-614, 2010.

HARRISON D, STEVENS B, BUENO M, YAMADA J, ADAMS-WEBBER T, BEYENE J, OHLSSON A: Efficacy of sweet solutions for analgesia in infants between 1 and 12 months of age: a systematic review. Arch Dis Child 95: 406-413, 2010.

HEINRICHER MM, TAVARES I, LEITH JL, LUMB BM: Descending control of nociception: specificity, recruitment and plasticity. Brain Res Rev 60: 214-225, 2009.

JANAL MN: Pain sensitivity, exercise and stoicism. J R Soc Med 89: 376-381, 1996.

JOHNSON SW, NORTH RA: Opioids excite dopamine neurons by hyperpolarization of local interneurons. $J$ Neurosci 12: 483-488, 1992.

KANAREK RB, HOMOLESKI B: Modulation of morphine-induced antinociception by palatable solutions in male and female rats. Pharmacol Biochem Behav 66: 653-659, 2000. 
KILLIAN P, HOLMES BB, TAKEMORI AE, PORTOGHESE PS, FUJIMOTO JM: Cold water swim stress- and delta2 opioid-induced analgesia are modulated by spinal gamma-aminobutyric acid A receptors. $J$ Pharmacol Exp Ther 274: 730-734, 1995.

KJAER A: Vasopressin as a neuroendocrine regulator of anterior pituitary hormone secretion. Acta Endocrinol (Copenh) 129: 489-496, 1993.

KOLTYN KF, BRELLENTHIN AG, COOK DB, SEHGAL N, HILLARD C: Mechanisms of exercise-induced hypoalgesia. J Pain 15: 1294-1304, 2014.

KOLTYN KF: Analgesia following exercise. Sports Med 29: 85-98, 2000.

KOOB GF: Drugs of abuse: anatomy, pharmacology and function of reward pathways. Trends Pharmacol Sci 13: 177-184, 1992.

LAU BK, VAUGHAN CW: Descending modulation of pain: the GABA disinhibition hypothesis of analgesia. Curr Opin Neurobiol 29: 159-164, 2014.

LEKNES S, TRACEY I: A common neurobiology for pain and pleasure. Nature Rev Neurosci 9: 314-320, 2008.

LEMLEY KJ, HUNTER SK, BEMENT MK: Conditioned pain modulation predicts exercise-induced hypoalgesia in healthy adults. Med Sci Sports Exerc 47: 176-184, 2015.

LI G, RHODES JS, GIRARD I, GAMMIE SC, GARLAND T JR: Opioid-mediated pain sensitivity in mice bred for high voluntary wheel running. Physiol Behav 83: 515-524, 2004.

MAIONE S, BISOGNO T, DE NOVELLIS V, PALAZZO E, CRISTINO L, VALENTI M, PETROSINO S, GUGLIELMOTTI V, ROSSI F, DI MARZO V: Elevation of endocannabinoid levels in the ventrolateral periaqueductal grey through inhibition of fatty acid amide hydrolase affects descending nociceptive pathways via both cannabinoid receptor type 1 and transient receptor potential vanilloid type-1 receptors. JPET 316: 969-982, 2006.

MCMORRIS T: Developing the catecholamines hypothesis for the acute exercise-cognition interaction in humans: Lessons from animal studies. Physiol Behav 165: 291-299, 2016.

MEEUSEN R, DE MEIRLEIR K: Exercise and brain neurotransmission. Sports Med 20: 160-188, 1995.

MEYER PJ, MORGAN MM, KOZELL LB, INGRAM SL: Contribution of dopamine receptors to periaqueductal graymediated antinociception. Psychopharmacology (Berl) 204: 531-540, 2009.

MOSELEY GL, PARSONS TJ, SPENCE C: Visual distortion of a limb modulates the pain and swelling evoked by movement. Curr Biol 18: R1047-R1048, 2008.

NEUBERT MJ, KINCAID W, HEINRICHER MM: Nociceptive facilitating neurons in the rostral ventromedial medulla. Pain 110: 158-165, 2004.

NIJS J, KOSEK E, VAN OOSTERWIJCK J, MEEUS M: Dysfunctional endogenous analgesia during exercise in patients with chronic pain: to exercise or not to exercise? Pain Physician 15 (3 Suppl): ES205-ES213, 2012.

ORBACH I, MIKULINCER M, KING R, COHEN D, STEIN D: Threshold and tolerance of physical pain in suicidal and nonsuicidal adolescents. J Consult Clin Psychol 65: 646-652, 1997.

PACAK K, PALKOVITS M, KOPIN IJ, GOLDSTEIN DS: Stress-induced norepinephrine release in the hypothalamic paraventricular nucleus and pitiutary-adrenocortical and sympatoadrenal activity: in vivo microdialysis studies. Front Neuroendocrinol 16: 89-150, 1995.

PACAK K, PALKOVITS M: Stressor specificity of central neuroendocrine responses: implications for stress-related disorders. Endocr Rev 22: 502-548, 2001.

PEREIRA EA, LU G, WANG S, SCHWEDER PM, HYAM JA, STEIN JF, PATERSON DJ, AZIZ TZ, GREEN AL: Ventral periaqueductal grey stimulation alters heart rate variability in humans with chronic pain. Exp Neurol 223: 574-581, 2010.

PUD D, GRANOVSKY Y, YARNITSKY D: The methodology of experimentally induced diffuse noxious inhibitory control (DNIC)-like effect in humans. Pain 144: 16-19, 2009.

RIZZOLATTI G, SINIGAGLIA C: The mirror mechanism: a basic principle of brain function. Nat Rev Neurosci 17: 757-765, 2016.

ROEDER Z, CHEN Q, DAVIS S, CARLSON JD, TUPONE D, HEINRICHER MM: Parabrachial complex links pain transmission to descending pain modulation. Pain 157: 2697-2708, 2016. 
SAWCHENKO PE, BROWN ER, CHAN RKW, ERICSSON A, LI H-Y, ROLAND BL, KOVÁCS KJ: The paraventricular nucleus of the hypothalamus and the functional neuroanatomy of visceromotor responses to stress. Prog Brain Res 107: 201-222, 1996.

SCOTT DJ, STOHLER CS, EGNATUK CM, WANG H, KOEPPE RA, ZUBIETA JK: Placebo and nocebo effects are defined by opposite opioid and dopaminergic responses. Arch Gen Psychiatry 65: 220-231, 2008.

SIMON EJ, HILLER JM: Opioid peptides and opioid receptors. In: Basic Neurochemistry: Molecular, Cellular And Medical Aspects 5th Ed. BRADY S, SIEGEL GJ, ALBERS RW, PRICE D (eds), Raven Press, New York, 1994, pp 321-338.

SIMS-WILLIAMS H, MATTHEWS JC, TALBOT PS, LOVE-JONES S, BROOKS JC, PATEL NK, PICKERING AE: Deep brain stimulation of the periaqueductal gray releases endogenous opioids in humans. Neuroimage 146: 833-842, 2017.

SLIMANI H, DANTI S, RICCIARDI E, PIETRINI P, PTITO M, KUPERS R: Hypersensitivity to pain in congenital blindness. Pain 154: 1973-1978, 2013.

SPARLING PB, GIUFFRIDA A, PIOMELLI D, ROSSKOPF L, DIETRICH A: Exercise activates the endocannabinoid system. Neuroreport 14: 2209-2211, 2003.

SPRENGER C, MAY A, BÜCHEL C: Pain contra pain: the concept of DNIC. Schmerz 24: 569-574, 2010.

STAGG NJ, MATA HP, IBRAHIM MM, HENRIKSEN EJ, PORRECA F, VANDERAH TW, PHILIP MALAN T JR: Regular exercise reverses sensory hypersensitivity in a rat neuropathic pain model: role of endogenous opioids. Anesthesiology 114, 940-948, 2011.

STANFORD SC: Central noradrenergic neurons and stress. Pharmac Ther 68: 297-342, 1995.

TAJET-FOXELL B, ROSE FD: Pain and pain tolerance in professional ballet dancers. Br J Sports Med 29: 31-34, 1995.

TASHIRO S, YAMAGUCHI R, ISHIKAWA S, SAKURAI T, KAJIYA K, KANMURA Y, KUWAKI T, KASHIWADANI H: Odour-induced analgesia mediated by hypothalamic orexin neurons in mice. Sci Rep 6: $37129,2016$.

TERMAN GW, SHAVIT Y, LEWIS JW, CANNON JT, LIEBESKIND JC: Intrinsic mechanisms of pain inhibition: activation by stress. Science 226: 1270-1277, 1984.

TOBALDINI G, SARDI NF, GUILHEN VA, FISCHER L: Pain inhibits pain: an ascending-descending pain modulation pathway linking mesolimbic and classical descending mechanisms. Mol Neurobiol 56: 1000-1013, 2019.

TORTA DM, DIANO M, COSTA T, GALLACE A, DUCA S, GEMINIANI GC, CAUDA F: Crossing the line of pain: FMRI correlates of crossed-hands analgesia. J Pain 14: 957-965, 2013.

VIANNA DM, BRANDÃO ML: Anatomical connections of the periaqueductal gray: specific neural substrates for different kinds of fear. Braz J Med Biol Res 36: 557-566, 2003.

VOGT BA, PANDYA DN: Cingulate cortex of the rhesus monkey: II. Cortical afferents. J Comp Neurol 262: 271-289, 1987.

WILDER-SMITH OH, SCHREYER T, SCHEFFER GJ, ARENDT-NIELSEN L: Patients with chronic pain after abdominal surgery show less preoperative endogenous pain inhibition and more postoperative hyperalgesia: a pilot study. J Pain Palliat Care Pharmacother 24: 119-128, 2010.

YAMAMOTOVÁ A, HRABÁK P, HŘÍBEK P, ROKYTA R: Do multiple body modifications alter pain threshold? Physiol Res 66 (Suppl 4): S493-S500, 2017.

YARNITSKY D, ARENDT-NIELSEN L, BOUHASSIRA D, EDWARDS RR, FILLINGIM RB, GRANOT M, HANSSON P, LAUTENBACHER S, MARCHAND S, WILDER-SMITH O: Recommendations on terminology and practice of psychophysical DNIC testing. Eur J Pain 14: 339, 2010.

YARNITSKY D, CRISPEL Y, EISENBERG E, GRANOVSKY Y, BEN-NUN A, SPRECHER E, BEST LA, GRANOT M: Prediction of chronic post-operative pain: pre-operative DNIC testing identifies patients at risk. Pain 138: 22-28, 2008.

ZUBEK JP, FLYE J, AFTANAS M: Cutaneous sensitivity after prolonged visual deprivation. Science 144: 1591-1593, 1964. 